\title{
Carolina Maria de Jesus e o pensamento liminar na literatura brasileira
}

\author{
Carolina Schenatto da Rosa' (iD) 0000-0001-5021-3782 \\ Gilberto Ferreira da Silva ${ }^{2}$ (i) 0000-0002-6294-2322 \\ 'Universidade do Vale do Rio dos Sinos, São Leopoldo, RS, Brasil. 93022-750. \\ 2Universidade La Salle, Canoas, RS, Brasil. 92010-000.
}

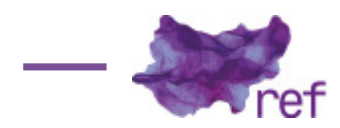

Resumo: Neste artigo tratamos da vida e obra de Carolina Maria de Jesus, tendo por base seus escritos publicados. Objetivamos, nesse sentido, problematizar, a partir da obra da referida autora, os reflexos da (des)colonialidade na construção das relações entre gênero e raça na sociedade brasileira. O estudo encontra amparo teórico no campo da (des)colonialidade, em diálogo com a pedagogia crítica e o feminismo. As análises reforçam o quanto a palavra escrita contribuiu com a densidade das percepções de Carolina acerca dos distintos espaços; ao dizer a sua palavra, aprendeu também a pensar a sua existência, aprendeu com a própria história em um contínuo refazer-se no ato da escrita. Ressaltamos a escrita engajada, seu potencial de denúncia e de anúncio, sua contribuição para o feminismo interseccional e, ainda, a relação indissocióvel entre feminismo e (des)colonialidade. Palavras-chave: Feminismo; escritoras negras; gênero; descolonialidade.

Carolina Maria de Jesus and Liminal Thinking in Brazilian Literature

Abstract: This paper portrays the life and work of Carolina Maria de Jesus, from her published writings. The purpose of it is to question the consequences of the (de)coloniality in the construction of the relation between gender and race in the Brazilian society, based on her books. The study is supported by (de)coloniality, in dialogue with critical pedagogy and feminism. The analysis reinforces how the written word contributed to the depth of Carolina's perceptions about the different spaces; by saying her word, she also learned how to think about her existence, she learned from her own history in a continuous remake of the written act. Therefore, it highlights her engaged writing, her potential of denouncement and announcement, her contribution to intersectional feminism, and, lastly, the inseparable relationship between feminism and (de)coloniality.

Keywords: Feminism; Black women writers; Gender; Decoloniality.

\section{Introdução}
Eu disse: o meu sonho é escrever! Responde o Branco: ela é louca O que as negras devem fazer... É ir pro tanque lavar roupa. Carolina Maria de Jesus

A colonialidade é um resquício tão violento, física e mentalmente, quanto foi a colonização dos países latino-americanos. A aniquilação de culturas, de histórias e de povos denunciada por Felipe Guaman Poma de Ayala (2005), Frantz Fanon (2010) e Aníbal Quijano (2005), entre tantos outros, ocasionou um processo sistemático de invisibilização das classes subalternas e de desumanização dos homens e mulheres que não se enquadram na metanarrativa colonial. Essa desumanização, diretamente relacionada com a invenção da categoria "raça" e sua vital influência no processo de colonização (QUIJANO, 2005), é, em grande medida, a responsável por, por exemplo, andarmos tranquilamente pelas calçadas enquanto mendigos dormem aos nossos 
pés, por fingirmos não estarmos vendo crianças sendo exploradas na lida precoce com o trabalho, por naturalizarmos a violência doméstica e, inclusive, por não estudarmos com profundidade e pouco mencionarmos as mulheres negras que contribuíram social, política e culturalmente para a construção de nosso país.

A noção de "raça" constitui-se como uma construção mental que serviu para dividir e organizar a sociedade em níveis e estabelecer hierarquias, relações de poder entre os povos superiores e inferiores (QUIJANO, 2005). Essa construção simbólica e violenta em torno da noção de raça(s) é tão forte que afeta há gerações os povos colonizados. Identidades raciais tornaramse identidades sociais quando foram associadas com valores éticos/morais, noções de bem e mal, de inferioridade e superioridade que caracterizaram o discurso justificador da colonização e da colonialidade (QUIJANO, 2005). A colonialidade, portanto, é um reflexo do processo colonial. É essa cegueira seletiva, porém (in)voluntária, que faz com que passados quase dois séculos da nossa independência e 130 anos da abolição da escravatura, ainda reproduzamos as identidades sociais e simbólicas associadas ao fator "raça" e seus desdobramentos.

$\mathrm{E}$, também, faz com que, ainda hoje, reproduzamos, juntamente com a hierarquização de raça, a hierarquização de gênero. Aprendemos com a pesquisadora Joan Scott (2010) que o debate sobre gênero exige o exercício da pergunta, exige que nos questionemos enquanto seres históricos sobre os papéis e lugares que assumimos enquanto seres sociais. Nesse sentido, não é possível pensarmos a colonialidade sem que a categoria gênero assuma, juntamente com a categoria raça, a centralidade do debate. Isso porque a hierarquização racial, que é base analítica do pensamento (des)colonial, nasce no bojo da hierarquização e binarização do gênero incutidas pela modernidade europeia. Ou seja, antes de construírem as identidades do "negro" e do "índio", os colonizadores reproduziram as identidades sociais do "homem" e da "mulher".

Existe um rol de mulheres negras brasileiras que contribuíram intelectualmente para as diversas áreas do saber. Entretanto, as barreiras da hierarquização de gênero e raça colocam-nas em uma situação de inferioridade que, infelizmente, atualiza diariamente a permanência da visão colonizadora racista e patriarcal. Com isso queremos ressaltar a necessidade das releituras, a necessidade de, a partir de uma perspectiva (des)colonial, (re)conhecer nossa história e suas personagens, assumindo que a intersecção entre as categorias gênero e raça é elemento fundante de nossa sociedade e do próprio pensamento (des)colonial.

Neste texto realizamos um breve estudo sobre a vida de Carolina Maria de Jesus - uma escritora internacionalmente reconhecida, cuja obra foi, por décadas, negligenciada pelos livros de literatura brasileira e cuja inspiradora biografia é desconhecida pela maior parte da população - tendo por base seus livros autobiográficos publicados. Como referência teórica, buscamos apoio em autores e autoras do campo da (des)colonialidade, a partir dos quais traçamos aproximações entre a história de Carolina e seus escritos com o campo da educação. Nosso objetivo, com isso, é problematizar, a partir da obra da referida autora, os reflexos da colonialidade do poder e do saber no papel e no lugar que as mulheres negras ocupam na história e na literatura brasileira.

Para dar conta de nosso objetivo, dividimos nossa reflexão em três momentos: primeiramente, em Autonarrativas de uma preta, pobre e favelada: a vida de Carolina de Jesus, apresentamos breves fragmentos da história de Carolina, desde sua infância em Minas Gerais até a migração para São Paulo e o início da escrita de seu diário. Em A escrita como denúncia: vislumbres da (des)colonialidade epistêmica, adentramos de forma mais intensa no nosso objetivo, relacionando a trajetória da escritora com o campo da (des)colonialidade. Por fim, em Da ascensão ao declínio: vida e obra às margens da história, problematizamos o silenciamento sofrido pela escritora após o lançamento do seu primeiro livro e o consequente apagamento de sua existência da história da literatura nacional. Retomamos nossos principais argumentos nas considerações finais.

\section{Autonarrativas de uma preta, pobre e favelada: a vida de Carolina de Jesus}

Como tantas outras mulheres negras pobres, Carolina poderia ter "nascido" para o silêncio, para o anonimato, para o mundo do trabalho, percurso considerado "natural" para sua condição no tempo e no local em que viveu. Entretanto, não foi exatamente assim. Pelo que se sabe, Carolina Maria de Jesus nasceu em 1914, em uma cidadezinha de Minas Gerais. Filha de mãe solteira, chegou a frequentar a escola regular - o que já representa muito nesse início de século -, mas, assim como tantas brasileiras e brasileiros, teve que abandonar os estudos para trabalhar, não chegando a completar o terceiro ano de estudo formal. Entretanto, isso não a impediu de desenvolver uma profunda paixão pela leitura. Sua passagem pelo Colégio Espírita Allan Kardec deve-se à Maria Leite Monteiro Barros - para quem a mãe de Carolina trabalhava como lavadeira -, que financiou sua alfabetização.

Foi na escola, ainda que em um curto período de tempo, que Carolina aprendeu seu nome. Até então era Bitita, se reconhecia e atendia apenas pelo apelido. Na escola virou Carolina, Carolina Maria de Jesus. A princípio, não se reconhecia nesse nome, não se via assim. A escola 
transformou Bitita em Carolina, um nome completo, composto. Bitita não sabia ler, Carolina sabia. Bitita não conhecia história escrita, Carolina conhecia. Bitita não sabia como pôr para fora seus pensamentos, como colocar no papel tudo que tinha na cabeça e no coração, mas Carolina sabia. Dois anos de escola não transformaram essa menina em outra pessoa, mas mostraram outras possibilidades. Carolina não deixou de ser Bitita, mas, capaz de compreender as palavras e o mundo, pôde ser mais. Essa é uma das grandes contribuições da leitura da palavra: possibilitar a releitura do mundo, não apenas a partir da cotidianidade, mas para além dela; releitura que ensina a generalizar, ou seja, ensina a perceber que experiências pessoais podem ser coletivas, podem representar padrões culturais e estruturas que transcendem a experiência em si (Paulo FREIRE, 2012).

No início da década de 1930, ela e sua mãe mudaram-se para São Paulo, para a cidade de Franca, onde trabalharam, especialmente, como empregadas domésticas. Quando adulta, após o falecimento da mãe, migrou para a cidade de São Paulo, onde começou a trabalhar em diversas funções, desde artista circense até empregada e lavadeira:

Carolina, sozinha no mundo, dormiu sob pontes, em estradas e lugares desprotegidos. Fez várias coisas para ganhar dinheiro, principalmente trabalhou como empregada doméstica. Foi também faxineira em hotéis, auxiliar de enfermagem em um hospital, vendeu cerveja, [...] algumas vezes tentou ser artista de circo (José Carlos MEIHY; Robert LEVINE, 1994, p. 21).

Quando engravidou, perdeu o emprego como doméstica e a moradia. Mudou-se para a Favela de Canindé, onde passou a trabalhar como catadora e lavadeira. Dos materiais que recolhia, construiu sua própria casa, alimentou seus três filhos e nutriu sua paixão pela palavra lendo e treinando a escrita a partir de velhas revistas e livros encontrados no lixo. No seu diário, ${ }^{1}$ primeira obra publicada, ela narra seu cotidiano e suas angústias:

Tudo quanto eu encontro no lixo eu cato pra vender. Deu 13 cruzeiros. Fiquei pensando que precisava comprar pão, sabão e leite pra Vera Eunice. E os 13 cruzeiros não dava! Cheguei em casa, aliás, no meu barracão, nervosa e exausta. Pensei na vida atribulada que eu levo. Cato papel, lavo roupa pra dois jovens, permaneço na rua o dia todo. E estou sempre em falta. A Vera não tem sapatos. E ela não gosta de andar descalça (JESUS, 1960, p. 09).

Os problemas narrados não são apenas de ordem pessoal; são, também, questões de classe. Questões que perpassam pela economia e pela política do país, pela cultura hegemônica marcada pela exclusão de raça e gênero que tanto incomoda a autora. Em suas reflexões sobre a realidade histórica e a condição social de "favelada" em que se encontra, conclui que até mesmo as aves têm condições de vida melhores do que as dos favelados, "que deitam e não dormem, porque deitam-se sem comer" (JESUS, 1960, p. 30). As injustiças cometidas contra sua classe foram uma das razões que a levaram a escrever e publicar seu primeiro diário: "aqui na favela todos lutam com dificuldades para viver. Mas quem manifesta o que sofre é só eu. Eu faço isso em prol dos outros" (lbidem, p. 32).

Fazia porque não acreditava em fatalidades, determinismos. Fazia porque compreendia a necessidade de denunciar as violências, anunciando transformações possíveis - como a sua própria transformação, que ocorreu por meio da leitura e da escrita. Fazia porque, tal qual Paulo Freire (2015), não se sentia inclinada "[...] mesmo quando me era ainda impossível compreender a origem de nossas dificuldades, a pensar que a vida era assim mesma, que o melhor a fazer diante dos obstáculos seria simplesmente aceitá-los como eram" (p. 41). Assim como nosso patrono da educação, Bitita sabia, desde muito cedo, que o mundo teria que ser mudado. Mais uma vez, podemos relacionar a vida e obra de Carolina com a pedagogia, por meio da práxis freireana, na qual o anúncio-denúncia é uma prática que não se desvincula da biografia político-existencial de cada um e cada uma (Célia LINHARES, 2018, p. 49).

A primeira escritora negra do Brasil a ter 7 obras publicadas, sendo o seu primeiro livro traduzido para 13 idiomas e vendido em mais de 40 países, teve pouco destaque na literatura nacional no final do século XX, sendo, comumente, lembrada e relacionada com um certo exotismo - tanto por sua história de vida, quanto pelas peculiaridades de sua escrita - que se sobrepunha, no discurso hegemônico, à qualidade crítica e estética de sua obra. Mediante a impossibilidade de apagá-la da história, virou objeto de estudos acadêmicos, uma parte quase inacessível da literatura brasileira. Sua vida e obra foram ressignificadas por meio de biografias, enquanto os manuscritos de seus diários (ou seja, sua voz) foram, por décadas, esquecidos pela própria academia. ${ }^{2}$

\footnotetext{
' Quarto de Despejo: diário de uma favelada, de 1960. Casa de Alvenaria: diário de uma ex-favelada, lançado em 1961. Pedaços de Fome, publicado em 1963 - mesmo ano da obra Provérbios. Diário de Bitita, postumamente publicado em 1982. Meu estranho Diário, obra organizada, publicada em 1996. Antologia Pessoal, publicação organizada por pesquisadores em 1996.

2 Parte de seus manuscritos, bem como outras fontes documentais, encontram-se disponíveis no arquivo Público Municipal Cônego Hermógenes Cassimiro de Araújo Brunswick, na cidade de Sacramento, MG. O material catalogado pode ser visto no site https://www.vidaporescrito.com/biblioteca-nacional. Acesso em 27/07/2019.
} 
Como exemplos de como a sociedade e a própria academia brasileira ressignificaram Carolina e transformaram-na em um objeto exótico do imaginário colonial (Walter MIGNOLO, 2003), citamos o título de sua primeira biografia: Cinderela negra - A saga de Carolina Maria de Jesus (MEIHY; LEVINE, 1994); e o título de uma das primeiras teses de doutorado defendidas sobre a autora: Carolina Maria de Jesus: o estranho diário da escritora vira-lata (Germana SOUSA, 2004). Títulos que reforçam esse imaginário construído sobre a autora como alguém que passou a ocupar um lugar que não lhe pertencia, que se transformou em algo que não era: uma escritora. Meihy e Levine (1994), inclusive, dizem que Carolina não se "'enquadrou' como escritora famosa". Há que se observar, ainda, outros dois aspectos da publicação e divulgação de suas obras que exemplificam essa exotização: o primeiro deles é a opção, por parte da editora, de alterar o conteúdo dos manuscritos (suprimir, reorganizar, ...) e manter a forma, o que evidencia um interesse em publicar os textos sem a verificação ortográfica - trabalho necessário em qualquer texto. 0 segundo deles é que o enfoque analítico sobre sua obra está centrado no discurso acadêmico que tenta interpretar sua escrita enquanto "estilo", como recurso literário.

É bem verdade que Carolina Maria de Jesus se transformou, entretanto, não foi por sua breve fama; ela se transformou quando aprendeu a ler o mundo e a dizer a sua palavra - o que fez por meio da escrita, quando passou a registrar seu cotidiano de forma crítica e profundamente reflexiva em seus diários. Carolina se transformou por questionar as péssimas condições de vida às quais ela e os seus vizinhos e vizinhas "favelados/as" eram submetidos por uma estrutura social injusta; por questionar as violências de gênero e raça. Ao contrário da Cinderela, ela nunca aceitou de forma passiva as injustiças e, tampouco, acreditou ou dependeu de um príncipe.

E é aqui que, em nossa visão, mora a "armadilha" da (des)colonialidade refletida na vida da Carolina: a ambiguidade. Não é possível voltar no tempo, apagar a história ou reescrevê-la; por isso, todos temos que viver com a herança colonial que formou nosso imaginário e construiu nossa história. No caso de Carolina, essa ambiguidade se manifesta na reprodução da retórica hegemônica, na qual ela era a Cinderela, salva por um príncipe e os outros eram os "favelados". A perspectiva (des)colonial não implica a ausência da colonialidade e de suas marcas, mas a vigilância na consciência crítica de que elas existem e precisam ser tensionadas. E é isso que, mesmo inconscientemente, a autora faz. Ela não se "livrou" dos imaginários colonializados; ela, muitas vezes, os reproduz; expondo suas prórprias tensões e, a partir delas, construindo sua visão crítica sobre a condição de mulher negra e de periferia; visão essa que, em muitos casos, entra em choque com a narrativa hegemônica.

A potência, na perspectiva crítica, de seus escritros está justamente no fato de ela não negar as condições ou características que a enquadravam como uma "escritora vira-lata"; pelo contrário, o que ela criticava era o fato de alguém de sua classe, gênero e raça não poder ocupar o espaço da "sala de visitas" na sociedade brasileira e, por consequência, na historiografia literária do país. Por essa razão, sua crítica é ao padrão de poder que se estende na atualidade, cuja dominação sócio-histórica já mencionamos no início deste texto - a colonialidade.

Em um de seus últimos livros, quando retoma o estilo de escrita dos diários, a autora conta com mais detalhes sua infância, rememorando que sua ida à escola não foi bem aceita pela mãe, que não via sentido nas aulas e preferia tê-la por perto para auxiliar nos trabalhos. Mas, como era o desejo de dona Maria Leite Barros, a patroa, acatou a benfeitoria e mandou Carolina para a escola. Segundo a autora, sua mãe "[...] dizia que os negros devem obedecer aos brancos, isto quando os brancos tem sabedoria. Por isso ela deveria enviar-me à escola, para não desgostar a dona Maria Leite" (JESUS, 1986, p. 123).

E essa possibilidade é um dos elementos centrais para compreendermos a importância de Carolina como uma figura representativa da pedagogia crítica, para compreendermos a importância de ler e reler o mundo e a sua própria história. A escrita da própria história, como Freire (2015) nos aponta em Cartas a Cristina: reflexões sobre minha vida e minha práxis, é uma tarefa política, antropológica e profundamente pedagógica. É uma forma de alfabetização política, de consciência da não neutralidade da escrita e da educação; de consciência de que o processo de alfabetização, enquanto ato de conhecimento, de libertação, exige um compromisso político com a transformação e a autorreflexão. Viver o tempo da escrita, das leituras e releituras é estudar(-se), pôr-se em contexto; e isso Bitita fez muito bem em seus diários. Ela sabia de onde estava falando, situando-nos no tempo e no espaço em que vivia. Os diários de Carolina de Jesus são fontes históricas de uma outra história do Brasil do século XX; isso é o que procuramos demonstrar a seguir.

\section{A escrita como denúncia: vislumbres da (des)colonialidade epistêmica}

Carolina de Jesus experimenta em sua existência, traduzida nas escritas e registros que produziu, atos (des)colonizadores, pois toma sua história de vida e seu contexto como referência para pensar e escrever. Se historicamente é o colonizador quem apresenta sua versão da história e seu registro, com Carolina temos a escrita de uma existência por quem a vive em toda sua 
intensidade e dramaticidade. Uma escrita que é assumida como estratégia, por exemplo, para vencer a fome, a dura e violenta realidade do cotidiano vivido por moradores de uma favela em São Paulo. Assim, Carolina nos brinda, em seus escritos, com um pensamento que não reproduz a lógica do pensamento hegemônico acadêmico, das leituras sociológicas e das "aventuras" antropológicas. É a escrita, quase que despida de pretensões com o domínio da própria língua, que se revela, evidenciando, ainda que de forma parcial, uma realidade existencial excessivamente crua e que perdura como retrato perfeitamente compreensível nos tempos atuais.

A autora acaba por produzir um "pensamento liminar", no sentido cunhado por Walter Mignolo (2003), pautado no reconhecimento da diferença colonial e da existência de perspectivas subalternas. Esse pensamento se expressa na escrita que soma a sua trajetória particular com tantas outras vozes que, ao longo do processo de colonização e colonialidade, foram sendo invisibilizadas como estratégia para que uma única forma de compreender e registrar o mundo ganhasse espaço e, portanto, se tornasse hegemônica. Ao tomar a palavra escrita para dizer o mundo e ao se tornar consciente de sua própria condição no mundo, Carolina produz um pensamento liminar que, ao evidenciar a diferença colonial, carrega o potencial da (des)colonialidade.

Explicaremos brevemente esses conceitos: a diferença colonial é uma construção de hierarquias e valores que se fundam e se estabelecem na relação entre a modernidade e a colonialidade (MIGNOLO, 2003). Em outras palavras, é a lógica de classificação e de hierarquização que foi construída para distinguir os europeus do restante do mundo, tendo como referência de humanidade e desenvolvimento seus próprios valores e sua própria história; ou seja, é o imaginário que permitiu a exploração de seres humanos por meio da distinção entre colonos e colonizados, brancos e negros, homens e mulheres, europeus e não europeus etc. Mignolo parte do conceito de "colonialidade do poder" - cunhado por Aníbal Quijano -, que será abordado no decorrer deste artigo, para conceber essa noção de distinção hierarquizada.

Neste contexto, a (des)colonialidade se apresenta como uma possibilidade de reconstrução deste imaginário das diferenças, sem que haja valoração ou hierarquização. É um processo permanente de luta e resistência contra a colonialidade e, por isso, contra o racismo e o patriarcado. Optamos pela grafia (des)colonialidade, que difere da forma cunhada por Quijano e Mignolo, entre outros, por acreditarmos que, dessa forma, a permanente "[...] tensão dialética entre a colonialidade e as resistências a sua imposição" (Cheron MORETTI; Telmo ADAMS, 2011) torna-se mais evidente. Resistências que se explicitam nos escritos de Carolina justamente pela intersecção que a autora faz em suas críticas sobre as distinções de gênero e raça que ela presenciava.

Tal qual a obra Nueva Corónica y buen Gobierno, escrita por Felipe Guaman Poma de Ayala séculos antes, o diário de Carolina, intitulado Quarto de Despejo, é um relato/denúncia da realidade injusta vivida por ambos e pelo povo. Tal qual Ayala, Carolina de Jesus usou como ferramenta para a denúncia sua arma mais poderosa; aquilo que, em certa medida, a diferia dos seus iguais e a aproximava das elites: a língua escrita. Ao contar as "desventuras" da vida de um favelado, sua narração não é isenta, é crítica e está para além se seu microambiente: entre os muitos relatos de seus dias como catadora e das dificuldades enfrentadas por sua família e seus vizinhos, como a falta de alimentos, saneamento ou energia, Carolina traça importantes relações a respeito da falta de comunicação entre o Estado e as comunidades e a ausência de políticas públicas. Em meados da década de 1950, em uma favela de São Paulo, Carolina Maria de Jesus escrevia em seus diários sobre a permanência da "[...] intersecção de gênero/classe/raça como construtos centrais do sistema de poder capitalista mundial" (María LUGONES, 2014, p. 939); ou seja, escrevia sobre feminismo interseccional, anticapitalista e, portanto, (des)colonial.

Em diferentes momentos as narrações revelam que era preciso catar alimentos no lixo para alimentar a família, marcando o contraponto do modelo econômico capitalista, que dita a vida de escassez na favela e a de excessos na cidade: "aos poucos os favelados estão convencendose que para viver precisam imitar os corvos. Eu não vejo eficiência do serviço social em relação ao favelado[...]" (JESUS, 1960, p. 41), constata a autora páginas antes de narrar sua ida às docas, onde ocorrera a cheia do rio e o alagamento dos armazéns em que eram estocados os alimentos. "Bem feito. Em vez de vender barato guarda esperando a alta dos preços: vi os homens jogar sacos de arroz dentro do rio. Bacalhau, queijo, doces. Fiquei com inveja dos peixes que não trabalham e passam bem" (Ibidem, p. 54). Enquanto Carolina e seus vizinhos "imitam corvos", catando comida velha no lixo, há comida sendo deixada para apodrecer e, depois, sendo jogada no rio, para que ninguém tenha acesso a ela.

Há, no diário, a percepção, por parte da autora, de que a acumulação dos alimentos é uma estratégia de mercado, visando ao maior lucro e que essa lógica prevê a perda e o descarte, mas não permite o consumo sem venda. Essa percepção fica clara mais adiante, quando o fato se repete e é novamente narrado. Desta vez, sacos de arroz que estavam em armazéns apodreceram: "Mandaram jogar fora. Fiquei horrorizada vendo o arroz podre. Contemplei as traças que circulavam, as baratas e os ratos que corriam de um lado para outro. Pensei: por que é que o homem branco é tão perverso assim? [...]" (JESUS, 1960, p. 130). 
Essa perversidade do homem branco no que diz respeito ao controle dos meios de produção e dos bens de consumo foi abordada teórica e epistemologicamente sob o conceito de "colonialidade do poder". Perspectiva amplamente utilizada e estudada pelo Grupo Modernidad/Colonialidad (M/C), que parte do princípio de que as relações de dominação nas esferas econômicas, políticas e sociais se mantiveram após o fim do período colonial (Luciana BALLESTRIN, 2013).

A pirâmide social desigual herdada da colônia e a própria criação das favelas, cuja origem está relacionada com a abolição da escravatura e com a substituição da mão de obra escrava pelos imigrantes europeus, são exemplos da colonialidade do poder. Esse movimento de "libertação" e substituição dos escravos gerou uma onda de miseráveis, sem terras, dinheiro ou emprego nas lavouras. Marginalizados pela sociedade e sem alternativas de subsistência, muitos tentaram migrar para os grandes centros urbanos, onde a industrialização ganhava força. Entretanto, novamente, perderam lugar - outra vez para os imigrantes europeus - e, sem alternativas, foram retirados das regiões centrais para áreas mais distantes, onde se formaram as favelas.

O fato de não serem empregados no campo e nem na cidade baseava-se em uma lógica simples: sua raça era considerada inferior às demais, sendo uma afronta exercer um trabalho remunerado. A colonialidade do poder baseia-se justamente nessa hierarquia racial. O padrão de poder que permitiu a conquista da América, a aniquilação de seu povo e a exploração de outros povos se fundamenta na ideia fatalmente simplista de que a raça branca é superior às demais e, por isso, pode dominá-las, ordená-las, ignorá-las, matá-las ou salvá-las, se assim quiser. Entretanto, cabe ressaltar que a hierarquia racial é precedida pela hierarquia de gênero que foi "importada" durante o processo de colonização e se fundiu na construção deste padrão de poder hegemônico.

Nesse ponto, o M/C - grupo composto majoritariamente por homens - também caiu na "armadilha" da (des)colonialidade, ao não negar a matriz patriarcal e heteronormativa que embasava suas próprias reflexões. Ao ingressar nesse coletivo, Lugones (2008) passa a problematizar o papel das relações de gênero na construção da colonialidade em suas três dimensões: o poder, o saber e o ser. Como essas três formas de opressão foram forjadas em uma sociedade machista e patriarcal, o gênero perpassa por todas essas construções de forma direta e indireta, formando, assim, uma quarta forma de dominação: a colonialidade de gênero. Essa dimensão da opressão, indissociável das demais, se constrói a partir das intersecções entre gênero, raça, classe e sexualidade. E é como uma maneira de resistir à essa colonialidade que compreendemos a trajetória de vida e a obra de Carolina Maria de Jesus.

Na década de 1950, enquanto a autora escrevia seus diários, o Brasil não trazia mais em seu vocabulário as palavras "colônia" e "escravidão"; o "país do progresso" vivia um crescente processo de industrialização, cuja modernização econômica trazia em suas bases os princípios de hierarquia de gênero e racial/étnica herdados da colônia. Apesar das transformações, o padrão de poder manteve-se solidificado tanto nas estruturas, quanto nas relações sociais e identidades societais (QUIJANO, 2009). Dadas as proporções, os relatos de Carolina têm tanta densidade reflexiva quanto as proposições teóricas que evocamos para abordar a temática da (des)colonialidade e servem de ilustração para o padrão de poder ao qual nos referimos.

De acordo com Quijano (2009), o poder constitui-se como espaço onde exploração, dominação e conflito se articulam em torno da disputa pelo controle dos meios de existência social. Esses meios são divididos em cinco categorias: o trabalho e os produtos; a natureza e os recursos para produção; o sexo (incluímos aqui as dimensões de gênero e sexualidade(s)); as subjetividades e intersubjetividades; e, por fim, a autoridade e os meios de assegurar a reprodução do padrão. Portanto, o controle dos meios de existência garante o domínio do padrão de poder, na mesma medida em que o domínio do padrão de poder facilita/assegura o controle dos meios de existência.

Carolina traduz o pensamento de Quijano e de Lugones para a vida cotidiana e faz referências às disputas pelos meios de trabalho, pelas relações de gênero e pela legitimação/ reprodução do padrão de poder colonial em seus escritos. Ao refletir sobre o processo de escravização e as suas consequências em seus diários, evidencia de forma bastante didática o processo da colonialidade e suas implicações ao longo do tempo:

Hoje amanheceu chovendo. [...] É o dia da Abolição. Dia que comemoramos a libertação dos escravos. [...]

[...] nas prisões os negros eram os bodes espiatorios. Mas os brancos agora são mais cultos. [...]. Que deus ilumine os brancos para que os pretos sejam feliz. [...]

E assim no dia 13 de maio de 1958 eu lutava contra a escravatura atual - a fome! (JESUS, 1960, p. 32).

Eu estava pensando na festa comemorativa da Abolição da escravatura. Mas temos outra pior - a fome. Conversei com um preto que é artista e ele disseme que gosta de ser preto. E eu também. Fiquei encantada com o preto João Batista Ferreira. É bonito estar satisfeito com o que somos. [...] A noite os barracões são todos negros. E negra é a existencia dos favelados (JESUS, 1961, p. 20). 
Pelos trechos acima apresentados, é possível perceber que a autora coloca sua história e sua condição como uma continuidade da escravatura, um reflexo da sociedade escravocrata que, para Carolina, continua mantendo mulheres negras e homens negros reféns do sistema de classes. Ciente da força daquilo que entendemos hoje por colonialidade do poder, essa mulher negra, migrante e favelada aprofunda suas reflexões, relatando a opressão de classe, de gênero e de raça que percebia na sociedade ao analisar as relações entre patrões e empregadas:

[...] Quando vencia o mês e a cozinheira recebia, ela tinha a impressão de ser uma heroína. Enaltecia a si mesma dizendo: - Eu sou forte! Não é qualquer um que aguenta cozinhar para o doutor Souza. Que orgulho, que vaidade ser a cozinheira do doutor José da Cunha ou do presidente Franklin Vieira e José Afonso. Era comum ouvir os ricos dizerem: - Sabe com quem está falando? Eu sou o manda-chuva. E as pretas pernósticas às vezes diziam: - Sabem com que cê tá falando? Eu sou a cozinheira do presidente. [...] Eram muitas pessoas pra trabalhar e pouquíssimos locais pra trabalhar. A patroa era tratada como se fosse uma santa no altar. Se as patroas estivessem nervosas, as empregadas deveriam dizer: - Sim, senhora! Se estivessem amáveis tinha que dizer: - Sim senhora! O homem pobre deveria gerar, nascer, crescer e viver sempre com paciência para suportar as filáucias dos donos do mundo. Se o filho do patrão espancasse o filho da cozinheira, ela não podia reclamar para não perder o emprego. Mas se a cozinheira tinha filha, pobre negrinha! $O$ filho da patroa a usaria para o seu noviciado sexual. Meninas que ainda estavam pensando nas bonecas, nas cirandas e cirandinhas eram brutalizadas pelos filhos do senhor Pereira, Moreira, Oliveira, e outros porqueiras que vieram do além-mar. No fim de nove meses a negrinha era mãe de um mulato, ou pardo. E o povo ficava atribuindo paternidade [...] Mas a mãe, negra, insciente e sem cultura, não podia revelar que seu filho era filho do doutor $X$ ou Y. Porque a mãe ia perder o emprego. Quantas mães solteiras se suicidavam, outras morriam tísicas de tanto chorar. O pai negro era afônico; se pretendia reclamar, o patrão impunha: - Cala a boca negro vadio! Vagabundo! E se o doutor Oliveira que estudou em Coimbra dissesse: - Negro ladrão... aquilo ia transferindo-se de boca em boca. E aquele negro, sem nunca ter roubado era um ladrão. E não se reabilitava jamais. [...] E o filho do senhor Oliveira, depois de farto de sedução de mocinhas pobres, decidia casar-se com a filha do senhor Moreira, ela era rica (JESUS, 1986, p. 34-35).

Conscientemente ou não, ela exemplifica em seu relato as relações de opressão abordadas por Quijano (2005), Lugones (2008) e Freire (2016), cuja fundação histórica está na colonização. Carolina percebe que as empregadas reproduzem o mesmo discurso de opressão que os seus patrões quando estão entre iguais. E percebe que, em relação às famílias empregadoras, brancas e ricas, a relação de poder desumaniza os oprimidos: não há verdade, não há direito, não há voz. Neste ponto, a Pedagogia do Oprimido vincula-se à teoria (des)colonial e ao pensamento do M/ C: intencionalmente ou não, seu processo de alfabetização, na segunda década do século XX, contribuiu para que ela fosse capaz de fazer múltiplas leituras do mundo e suas traduções para a palavra (FREIRE, 2016), o que possibilita um processo de reflexão, de autoconhecimento e de resistência. Assim, ao fazê-lo, ela rompe com o ciclo da opressão e da colonialidade: "Eu fiz uma reforma em mim. Quero tratar as pessoas que conheço com mais atenção. Quero enviar um sorriso amável as crianças e aos operários" (JESUS, 1960, p. 25).

A leitura do mundo, nessa perspectiva, exige reflexão e transformação. Reflexão para compreender o mundo, a si mesma e a si mesma no/com o mundo; e transformação enquanto ato criativo capaz de modificar essa relação no/com o mundo na medida em que a compreende. $\mathrm{E}$ essa é outra das contribuições da leitura da palavra, do aprendizado da escrita para a educação transformadora: a amorosidade, a capacidade de ver o outro como um igual. Não se trata de hierarquizar a alfabetização ou a cultura escrita em detrimento às demais formas de ser/estar no mundo; mas se trata de perceber a importância que esse aprendizado teve para Carolina, que foi o de humanizá-la, na perspectiva freireana. "Tenho apenas dois anos de grupo escolar, mas procurei formar meu caráter. A única coisa que não existe na favela é solidariedade" (JESUS, 1960, p. 13). Nesta passagem a autora fala de como as crianças eram tratadas, da ausência de respeito, paciência e amor. Nesse contexto, ao falar de seu tempo na escola, de seu processo de alfabetização, ela fala em solidariedade; um valor essencial para transformarmos o mundo e a nós mesmos. Um valor que reforça seu processo de conscientização.

Esse processo de conscientização, diretamente relacionado com as leituras de mundo e da palavra e, portanto, profundamente pedagógico, é parte fundante daquilo que Lugones (2014) chama de feminismo (des)colonial, pois "descolonizar o gênero é necessariamente uma práxis. É decretar uma crítica da opressão de gênero racializada, colonial e capitalista heterossexualizada visando a uma transformação vivida do social" (p. 940). Carolina exercitou essa práxis, assumindo uma postura radical e (des)colonial durante a sua trajetória. Carolina criou formas de resistência e de (r)existência.

Essa crítica perpassa pela relação centro/periferia e pela distribuição geográfica do capitalismo abordadas por Quijano (2005), que não ocorrem apenas no cenário macro e nas relações entre países colonizadores e colonizados; elas se reproduzem em cenários micro, como a 
geografia das cidades, por exemplo. As características geoculturais do colonialismo (QUIJANO, 2009), que atribuem padrões hierárquicos a partir da localidade, são marcadas pelo dualismo entre civilizado/primitivo, moderno/ultrapassado, capazes/incapazes, que constituem o pensamento tradicional eurocêntrico e replicam-se na relação entre centro e favela, como é evidenciado por Carolina em seu diário: "quando estou na cidade tenho a impressão que estou na sala de visita com seus lustres e cristais, seus tapetes de viludos, almofadas de sitim. E quando estou na favela tenho a impressão que sou um objeto fora de uso, digno de estar num quarto de despejo" (JESUS, 1960, p. 35).

Entretanto, no quarto de despejo Carolina não se deixou objetificar. Ciente das relações de subserviência e dominação decorrentes da distinção de raça e gênero, lutou por sua autonomia e buscou não se submeter às opressões interseccionais, à condição de propriedade, de coisa e, na maioria das vezes, de objeto sexual para os homens. Mãe solteira e chefe de família, a autora faz questão de deixar claro em suas obras que optou por não se casar em função das violências que presenciava na favela e por acreditar que nenhum homem "[...] há de gostar de uma mulher que não pode passar sem ler. E que levanta para escrever. E que deita com lápis e papel debaixo do travesseiro. Por isso é que eu prefiro viver só pra o meu ideal" (JESUS, 1960, p. 50). Esse pequeno excerto exemplifica uma postura, uma forma de ser que se opõe à lógica patriarcal, que se opõe a todas as dimensões da colonialidade de gênero. Ser mãe solteira e trabalhadora não era uma vergonha, era um orgulho, uma opção:

Elas alude que não sou casada. Mas eu sou mais feliz do que elas. Elas tem marido. Mas, são obrigadas a pedir esmolas. São sustentadas por associações de caridade.

Os meus filhos não são sustentados com pão de igreja. Eu enfrento qualquer especie de trabalho para mante-los. E elas, tem que mendigar e ainda apanhar. Parece tambor. A noite enquanto elas pede socorro eu tranquilamente no meu barracão ouço valsas vienenses. Enquanto os espôsos quebra as tabuas do barracão eu e meus filhos dormimos socegados. Não invejo as mulheres casadas da favela que levam vida de escravas indianas (JESUS,1960, p. 1718).

Essa Cinderela não queria um príncipe. Sua busca por autonomia e independência, traduzida na vontade de ser dona de si, falar por si e lutar por suas escolhas, reflete-se no processo de conscientização (FREIRE, 2016), ou seja, no desenvolvimento crítico-reflexivo da compreensão da realidade. Percebemos que a denúncia biográfica compreende esse processo de conscientização, uma vez que Carolina tem consciência da realidade e a expõe, por meio de seu relato, mas, também, tem consciência das responsabilidades dos outros setores da sociedade. No trecho que apresentamos a seguir a autora não apenas relata que as condições de pobreza e violência da favela não são de responsabilidade dos moradores, como sugere qual seria uma das funções das instituições de segurança pública e a quem cabe solucionar a questão:

O tenente interessou-se pela educação dos meus filhos. Disse-me que a favela é um ambiente propenso, que a pessoa tem mais possibilidades de delinqüir do que tornar-se útil a pátria e ao país. Pensei: se ele sabe disto, porque não faz um relatorio e envia para os políticos? O senhor Janio Quadros, o Kubstchek e o Dr. Adhemar de Barros? Agora falar para mim, que sou uma pobre lixeira. Não posso resolver nem as minhas dificuldades (JESUS, 1960, p. 31).

A análise deste pequeno excerto nos mostra duas percepções distintas sobre responsabilidade social quanto ao lugar geocultural que a favela ocupa. O "interesse" do tenente em alertar sobre os riscos da vida em Canindé aponta como solução a saída da favela, a troca daquele mundo por outro melhor. A reflexão da autora, por sua vez, aponta como solução a transformação da favela em um mundo melhor, em lugar do fatalismo binário que torna necessária a existência da miséria e da violência para a reprodução do padrão de poder hegemônico.

Entretanto, é necessário considerar que a posição de Carolina com relação à transformação da favela não exclui seu desejo latente de sair deste ambiente. Aliás, assim que as vendas de Quarto de Despejo: diários de uma favelada dão retorno financeiro, a autora vai morar com seus filhos em outra região da cidade, onde começa a escrever segundo livro: Casa de Alvenaria: diários de uma ex-favelada. Apesar de o título evidenciar a ascensão social da família, a segunda obra trouxe críticas ainda mais profundas ao modelo socioeconômico do país e à ineficiência das políticas públicas, mostrando que sua saída de Canindé foi apenas mais uma migração desta catadora de estórias cotidianas.

\section{Da ascensão ao declínio: vida e obra às margens da história}

"Agora eu falo e sou ouvida. Não sou mais uma negra suja da favela" (JESUS, 1961, p. 17), disse Carolina ainda nas primeiras páginas de Casa de Alvenaria. O segundo livro reúne registros do primeiro ano após o lançamento de Quarto de Despejo, mostrando as dificuldades de adaptação à nova realidade e de diálogo com o mercado editorial. A autora se sente usada pela 
mídia, por seu editor e pela sociedade; a negra escritora virou um objeto exótico, sendo explorada por aqueles que ansiavam por sua ajuda, pelos que tinham interesse em sua imagem e, ainda, por aqueles que não toleram a quebra no padrão de poder que uma escritora negra e mãe solteira representa.

Apesar de estar na "sala de visitas" da sociedade, a autora continuava a não fazer parte daquele mundo; era uma selvagem, uma bárbara em um universo civilizado. Mulher autônoma e crítica, não se enquadrou no imaginário da favelada humilde e agradecida, que via sua presença na "sala de visitas" como um favor, uma benevolência: "...Varias senhoras vieram falar de pobreza para mim, dizendo que eu devo resolver a condição desumana dos favelados do Pais. Eu apresentei os fatos. Compete aos burgueses que predominam no Pais solucionar..." (JESUS, 1961, p. 96).

Sua postura, suas opiniões e seu modo de vida destoavam do espaço-tempo em que estava inserida: seu tempo não era gasto com a limpeza da casa, na cozinha, com a roupa das crianças e nem com homens que passavam por sua vida; sua dedicação era com o aprendizado e com a escrita, ou seja, com sua independência dos padrões de comportamento estipulados tanto para aquelas mulheres que viviam na sala de visitas, quanto para aquelas que ocupavam o quarto de despejo. Neste sentido, Carolina rompe duplamente com o padrão hierárquico colonial pela intersecção entre gênero e raça, que demarca um violento arremesso - fazendo uso da expressão de Gayatri Spivak (2010) - das mulheres do "terceiro mundo" para o quarto de despejo.

A legitimidade do caráter reflexivo e cultural da obra de Carolina é constantemente posta em xeque pela colonialidade, que nega os entre-lugares, os amasamientos (Gloria ANZALDÚA, 2000) que transformam o debate de gênero e raça na América Latina parte de uma outra cultura, uma nova história, com novos sistemas de valores que compreendem o mundo tendo em vista a participação ativa das mulheres (negras, mestiças, índias, lésbicas, ...) nele. Em uma carta para as mulheres escritoras do Terceiro Mundo, Anzaldúa (2000) enfatiza que é na intersecção entre gênero e raça que reside com mais força a colonialidade, salientando que "os perigos que enfrentamos como mulheres de cor não são os mesmos das mulheres brancas, embora tenhamos muito em comum. Não temos muito a perder - nunca tivemos nenhum privilégio" (p. 229).

Esses perigos, no campo da literatura, tornam os escritos de mulheres negras mais do que invisíveis, pois a existência destas escritoras é simplesmente negada,

porque os olhos brancos não querem nos conhecer, eles não se preocupam em aprender nossa língua, a língua que nos reflete, a nossa cultura, o nosso espírito. As escolas que frequentamos, ou não frequentamos, não nos ensinaram a escrever, nem nos deram a certeza de que estávamos corretas em usar nossa linguagem marcada pela classe e pela etnia (ANZALDÚA, 2000, p. 229).

Como é possível perceber ao longo da obra de Carolina, a autora traz em seus textos uma linguagem própria, marcada pela singularidade de seu contato com a língua escrita. Para além das questões da gramática e da ortografia, a escritora traz em seu vocabulário as "marcas de classe e etnia" que Anzaldúa menciona em sua carta, provando que seus usos eram corretos e tão inteligíveis quanto os textos de qualquer obra dita "clássica" da literatura. Mesmo sendo censurada por sua linguagem, como admite ao relatar que "[...] alguns criticos dizem que sou pernostica quando escrevo", Carolina não abre mão de suas marcas de linguagem e questiona: "será que preconceito existe até na literatura? O negro não tem direito de pronunciar o classico?" (JESUS, 1961, p. 63-64).

Ao ocupar os espaços da "sala de visita", a escritora passa a ser assediada pela mídia, que questiona a legitimidade de seus posicionamentos e suas críticas sociais uma vez que, após a fama, Carolina não "resolveu" nenhum dos problemas que denunciou em seu primeiro livro. Diante da acusação, ela responde ao jornalista José Álvaro (1960):

Escrevendo, já estou cumprindo uma missão social, destacando um sério problema social. 0 meu ideal é escrever. Por que ele, como um grande industrial não melhora os salários dos seus trabalhadores? E mesmo que eu fizesse uma obra de caridade e conseguisse um milhão, por exemplo. Que é que adiantaria? O milhão ia acabar um dia e os pobres ficariam na minha porta e ainda pensariam que eu tinha ficado com o dinheiro deles (p. 5).

A autora explicita, na fala destacada acima, a sua compreensão sobre a sociedade de classes e sobre a questão estrutural que impõem o modelo de exploração e dominação vigente. Ela evidencia sua clareza quanto à ineficiência de ações pontuais, e quanto ao seu papel de mulher, escritora e intelectual de denunciar a realidade e anunciar possibilidades. Carolina tinha consciência de que sua alfabetização política era uma ferramenta de denúncia e de conscientização.

A radicalidade da Casa de Alvenaria, livro no qual a autora fez duras críticas ao sistema político e social, culpando diretamente os governantes pela pobreza do povo, fez com que Carolina fosse considerada comunista e mal vista pela imprensa, que a caricaturava como pouco civilizada, inculta e de temperamento instável. A construção da noção de raça e os estereótipos de gênero 
foram extremamente explorados pela mídia e pelos discursos hegemônicos, fazendo com que, a partir de seu segundo livro, as publicações não tivessem sucesso nas vendas. O terceiro livro foi pago com seu próprio dinheiro e vendeu poucos exemplares. A quarta obra recebeu duras críticas e foi considerada "mais do mesmo".

Por sua história e suas posições Carolina foi condenada ao ostracismo. Menos de uma década após o lançamento de Quarto de Despejo, ela deixou sua casa de alvenaria e retornou ao "quarto de despejo". Sem reconhecimento e sem dinheiro, a escritora mudou-se para a periferia de São Paulo retomando sua rotina de trabalho como catadora para garantir o sustento. Morreu em 1977 e permaneceu esquecida por décadas. Agora, aos poucos, vem sendo redescoberta e estudada pela literatura, mas suas contribuições pedagógicas seguem invisibilizadas.

\section{Considerações finais}

Contraste e confronto. Essas são as palavras utilizadas pela escritora ao narrar a visita de um coronel à parte pobre da cidade de São Paulo, no romance Casa de Alvenaria. Carolina fala em "Iuxo nanabesco e miséria dantesca" para retratar a cidade, mas essas expressões servem para muito mais: são um retrato preciso do Brasil e uma síntese daquilo que critica em sua obra. Carolina Maria de Jesus apresentou os contrastes e partiu para o confronto: foi a público, falou, mostrou-se para o mundo como mulher negra, favelada e escritora. Ela foi uma crítica severa das desigualdades, uma escritora politicamente comprometida.

Neste artigo buscamos olhar para a história desta escritora e recontá-la a partir da perspectiva da (des)colonialidade, pois entendemos que as violências narradas/vividas por Carolina, assim como por muitas outras mulheres deste país, são a exemplificação daquilo que compreendemos como colonialidade (seja ela do poder, do saber, do ser ou do gênero); e evidenciam que não é possível problematizar ou compreender esse padrão de poder desassociando gênero e raça. A violência colonial é interseccional, e, portanto, não conseguimos conceber formas de resistência que não o sejam.

Consciente de sua situação de opressão, ela ousou dizer a sua palavra, denunciar os contrastes sociais que percebia na sociedade e confrontá-los por meio de sua escrita. A forma encontrada pela autora para esse confronto - a escrita de seus diários - foi, ao nosso entender, uma forma de autodescoberta, de autorreflexão; uma forma de colocar suas percepções sobre a vida, a exploração e a miséria em diálogo com outros conhecimentos existenciais, outras experiências de vida. Seus diários evidenciam as geografias, as fronteiras de classe, gênero e raça existentes no Brasil dos anos de 1940, 1950, 1960 e, infelizmente, no Brasil de hoje, do século $X X I$. As fronteiras entre os que comem muito e os que comem pouco, entre os que exploram e são explorados, entre os que batem e os que apanham, ...enfim, entre aqueles que são compreendidos como oprimidos e aqueles que reproduzem a opressão.

Retomamos aqui o papel central da escrita autobiográfica enquanto forma de dizer a sua palavra, ou seja, enquanto processo reflexivo e alternativa prática de tomar para si seu processo formativo, a consciência de sua existência e o poder de transformação de sua resistência. Nessas tantas fronteiras, foi a palavra escrita que permitiu o trânsito, a passagem das percepções de Carolina pelos distintos espaços. Dizer a sua palavra, como afirma Ernani M. Fiori (2016), é isso, é aprender a pensar a sua existência, é aprender a própria história e aprender com a própria história em um contínuo refazer-se; reescrever-se. E esse movimento de constante transformação, de resistência, de respeito à própria história, é o que constitui a (des)colonialidade.

Não há (des)colonialidade sem educação, sem uma perspectiva crítica e autorreflexiva sobre si mesma/o e sobre sua relação com o mundo; tampouco pode haver (des)colonialidade que não seja feminista. É isso que Carolina fez: escreveu a própria história, mostrou as limitações de seu pensamento, expôs as contradições da colonialidade em suas denúncias e, a partir delas, anunciou um mundo novo; um mundo onde uma mulher negra não está condicionada ao tanque, um mundo no qual seus diários são lidos, também, na sala de jantar.

\section{Agradecimentos}

À CAPES e ao CNPq, pelas bolsas para a realização do Mestrado e do Doutorado.

\section{Referências}

ÁLVARO, José. "Da favela au bon gourmet”. Tribuna da Imprensa. Rio de Janeiro, $2^{\circ}$ caderno, p. 5 , 05/12/1960.

ANZALDÚA, Gloria E. "Falando em línguas: uma carta para as mulheres escritoras do terceiro mundo". Revista Estudos Feministas, Florianópolis, v. 8, n. 1, p. 229-236, 2000. Disponível em https:// www.sertao.ufg.br/up/16/o/anzaldua.pdf. Acesso em 26/07/2019. ISSN 1806-9584 
BALLESTRIN, Luciana. "América Latina e giro decolonial". Revista Brasileira de Ciência Política, Brasília, n. 11, p. 89-1 17, 2013. Disponível em http://periodicos.unb.br/index.php/rbcp/article/view/ 2069. Acesso em 26/07/2019. ISSN 2178-4884

FANON, Frantz. Os condenados da terra. Juiz de Fora: EDUFJF, 2010.

FIORI, Ernani M. "Prefácio: Aprender a dizer a sua palavra". In: FREIRE, Paulo. Pedagogia do Oprimido. Rio de Janeiro: Paz e Terra, 2016. p. 11-30.

FREIRE, Paulo. Pedagogia do Oprimido. Rio de Janeiro: Paz e Terra, 2016.

FREIRE, Paulo. Cartas a Cristina: reflexões sobre minha vida e minha práxis. 2. ed. São Paulo/Rio de Janeira: Paz e Terra, 2015.

FREIRE, Paulo. Professora sim, tia não. Rio de Janeiro: Paz e Terra, 2012.

JESUS, Carolina Maria de. Quarto de Despejo: diário de uma favelada. São Paulo: Francisco Alves, 1960.

JESUS, Carolina Maria de. Casa de alvenaria: diário de uma ex-favelada. Rio de Janeiro: Paulo de Azevedo, 1961.

JESUS, Carolina Maria de. Diário de Bitita. Rio de Janeiro: Nova Fronteira, 1986.

LINHARES, Célia. "Anúncio/Denúncia". In: STRECK, Danilo; REDIN, Euclides; ZITKOSKI, Jaime. Dicionário Paulo Freire. 4. ed. rev. amp. Belo Horizonte: Autêntica, 2018. p. 45-74.

LUGONES, María. “Colonialidade e gênero". Revista Tabula Rasa, Bogotá, n. 9, p. 73-101, 2008. Disponível em http://www.revistatabularasa.org/numero-9/05lugones.pdf. Acesso em 26/07/2019. ISSN 1794-2489

LUGONES, María. "Rumo a um feminismo descolonial". Revista Estudos Feministas, Florianópolis, v. 22, n. 3, p. 935-952, 2014. Disponível em https://periodicos.ufsc.br/index.php/ref/article/view/36755/ 28577. Acesso em 26/07/2019. ISSN 1806-9584

MEIHY, José Carlos S. B.; LEVINE, Robert M. Cinderela Negra: a saga de Carolina Maria de Jesus. Rio de Janeiro: EDUFRJ, 1994.

MIGNOLO, Walter. Histórias Globais/projetos Locais. Colonialidade, saberes subalternos e pensamento liminar. Belo Horizonte: EDUFMG, 2003.

MORETTI, Cheron Z.; ADAMS, Telmo. "Pesquisa participativa e educação popular: epistemologias do sul". Revista Educação e Realidade, Porto Alegre, v. 36, n. 2, p. 447-463, 2011 . Disponível em https://seer.ufrgs.br/educacaoerealidade/article/view/16999/12915. Acesso em 26/07/2019. ISSN $2175-6236$

POMA DE AYALA, Felipe Guaman. Nueva Corónica y Buen Gobierno. Lima: Fondo de Cultura Económica, 2005.

QUIJANO, Aníbal. "Colonialidade do poder, eurocentrismo e América Latina”. In: LANDER, Edgardo (Org.). A colonialidade do saber: eurocentrismo e ciências sociais. Perspectivas latinoamericanas. Buenos Aires: CLACSO, 2005. p. 118-142. (Colección Sur Sur)

QUIJANO, Aníbal. "Colonialidade do poder e classificação social". In: SANTOS, Boaventura de Sousa; MENESES, Maria Paula. Epistemologias do Sul. Coimbra: Almedina, 2009.

SCOTT, Joan W. "Gender: still a useful category of analysis?". Diogenes, Durham, v. 57, n. 1, p. 7-14, 2010. Disponível em https://sites.duke.edu/his1 80/files/2014/08/Scott_Gender-Still-a-Useful-Categoryof-Analysis.pdf. Acesso em 26/07/2019. ISSN 0392-1921 DOI 10.1177/0392192110369316

SOUSA, Germana Henriques Pereira de. Carolina Maria de Jesus: o estranho diário da escritora vira-lata. 2004. Tese (Doutorado em Teoria Literária) - Programa de Pós-Graduação em Literatura, Universidade de Brasília, Brasília, DF, Brasil.

SPIVAK, Gayatri Chakravorty. Pode o subalterno falar? Belo Horizonte: EDUFMG, 2010. 
Carolina Schenatto da Rosa (carolinaschenatto@gmail.com) é doutoranda em Educação pelo Programa de Pós-Graduação em Educação da Universidade do Vale do Rio dos Sinos/Unisinos. Mestra em Educação pelo Programa de Pós-Graduação em Educação da Universidade La Salle. Integrante do Grupo de Pesquisa Mediações Pedagógicas e Cidadania e do Grupo de Pesquisa em Educação Intercultural.

Gilberto Ferreira da Silva (gilberto.ferreira65@gmail.com) é Professor do Programa de Pós-Graduação em Educação e do curso de Pedagogia da Universidade La Salle, onde coordena a Linha de Pesquisa: Formação de Professores, Teorias e Práticas Educativas. É líder do Grupo de Pesquisa em Educação Intercultural e editor adjunto da Revista Educação, Ciência e Cultura.

\section{COMO CITAR ESSE ARTIGO DE ACORDO COM AS NORMAS DA REVISTA}

ROSA, Carolina Schenatto da; SILVA, Gilberto Ferreira da. "Carolina Maria de Jesus e o pensamento liminar na literatura brasileira". Revista Estudos Feministas, Florianópolis, v. 28, n. 2, e60635, 2020.

\section{CONTRIBUIÇÃO DE AUTORIA}

Carolina Schenatto da Rosa: Leitura dos livros de Carolina Maria de Jesus, apropriação teórica e escrita do texto.

Gilberto Ferreira da Silva: Sugestões teóricas, escrita do texto e revisão do manuscrito.

\section{FINANCIAMENTO}

O presente trabalho foi realizado com apoio da Coordenação de Aperfeiçoamento de Pessoal de Nível Superior - Brasil (CAPES) - Código de Financiamento 001.

\section{CONSENTIMENTO DE USO DE IMAGEM}

Não se aplica.

\section{APROVAÇÃO DE COMITÊ DE ÉTICA EM PESQUISA}

Não se aplica.

\section{CONFLITO DE INTERESSES}

Não se aplica.

\section{LICENÇA DE USO}

Este artigo está licenciado sob a Licença Creative Commons CC-BY International. Com essa licença você pode compartilhar, adaptar, criar para qualquer fim, desde que atribua a autoria da obra.

\section{HISTÓRICO}

Recebido em 11/12/2018

Reapresentado em 29/07/2019

Aprovado em 26/08/2019 